\title{
Design of Education Application based on Shiva 3D Platform
}

\author{
https://doi.org/10.3991/ijet.v12i04.6685 \\ Sun Hui \\ Civil Aviation University of China, Tianjin, China \\ shhappy 1 @ hotmail.com
}

\begin{abstract}
With the popular spread of electronic products, more and more related applications based on a virtual platform are being utilized. Meanwhile, more and more concerns are surfacing about the implementation of the functionality of virtual reality technology in the education or training field. The paper gives a specific example to propose the characteristics of a gaming education application based on Shiva 3D game engine. The implementation of this kind of application indicates that virtual reality technology of video games can be used in self-learning in education and training and can have significant results.
\end{abstract}

Keywords-Virtual Reality; Shiva3D game engine; education; training application

\section{Background}

With the development of the video game industry, more and more people like playing games to relax themselves from their busy career and family commitments. The video game industry in United States approaches yearly revenues of $\$ 15$ billion. Digital games (video games or computer games) are quickly accepted by children and teenagers. In the United States, the range of the game playing population has changed from between 14 to 19 years old to between the ages of 10 to 34 years old.

Currently, games are not just a tool for entrainment. The video game becomes an important vehicle for education. This kind of game is called an educational game. The educational game provides teachers and students a useful tool to create opportunities for enhanced learning of knowledge. In this case, the educational game has being used in E-learning for school teaching processes.

It is well-known that E-learning is a method which can transfer knowledge by using computer and network-enabled skills. In particular, it allows a learner to study at their own pace, at any time that they choose by themselves, and in the order that they prefer [2]. E-learning includes Web-based learning, computer-based leaning, virtual educational opportunities and digital collaboration. The third generation of E-learning is a more collaborative learning environment based much more on the constructivist epistemology, promoting reflective practice through tools such as online communities and using interactive technologies, e.g., games and simulations [3]. 
The reason why games become a viable tool for studying and learning is its characteristics. Video game technology has an impact on childhood education because the video games have the capacity to engage children in learning experiences. Video games are also more effective for children who start out with relatively poor skills. Games have four attributes, i.e., expression, interaction, conflict and safety (C. Crawford, 1984), which make it possible to solve operational learning problems in a more meaningful way [4]. According to [5], video games were used in special needs groups, for example, the video games can help develop social skills in children and adolescents who have severe developmental problems like autism. Video games have also made a great functionality in brain-wave biofeedback research, health care and rehabilitation.

In universities, teachers are typically using video games to train students in technical fields like Electrical and Computer Engineering. Games can abstract the interest of the students. During playing a game, the students utilize their skills to learn the game and perform better every time they play. This provides immediate, positive reinforcement that motivates further practice. In the natural flow of gaming, students learn the technical aspects of the subjects, which can be used in the real world [6]. Educational Games can be integrated into higher education in three ways.

First, games can replace traditional exercises motivation. The students will put extra effort in doing the exercises. At the same time, this also gives the teacher and teaching assistants an opportunity to monitor real-time how the students work with the exercises in the real world [7].

Second, games can be simultaneously used with lectures to improve the participation and motivation of students [8]. For this approach, the students and the teacher participate in knowledge-based games.

Third, the students are required to develop a game as a part of the course using a game development framework (GDF) in order to learn the skills of science or engineering [9].

The following is an example in Figure 1.

Mobile Game-Based Science Learning describes a pedagogical methodology based on interactive games for mobile devices (PDAs). The methodology is oriented to developing problem-solving skills in science classes for 8th graders, by including preclassroom activities with the teacher, classroom activities, and a central activity using an interactive game for a mobile device. The core problem they have to solve through the game consists of preserving and evolving different biological species from the animal kingdom, in an unknown and varying environment, by modifying some key factors for evolution of the species[7].

Another example is a smart phone. In recent years, smart phones have now become increasingly popular. There are 400,000 iPhones that have been sold in Norway alone [11]. The population of this country is only 4.8 million. More and more students use hand-held phones every day in most countries. Currently, iPhone is the most popular smart phone. An important benefit of iPhone is that it is user-friendly - easy to learn for both work and entertainment. A popular feature of the iPhone is a touch screen technology. In addition, the special effect of an iPhone application is very attractive to use. So, the increasing educational games are published on this ideal tool. As a result, 


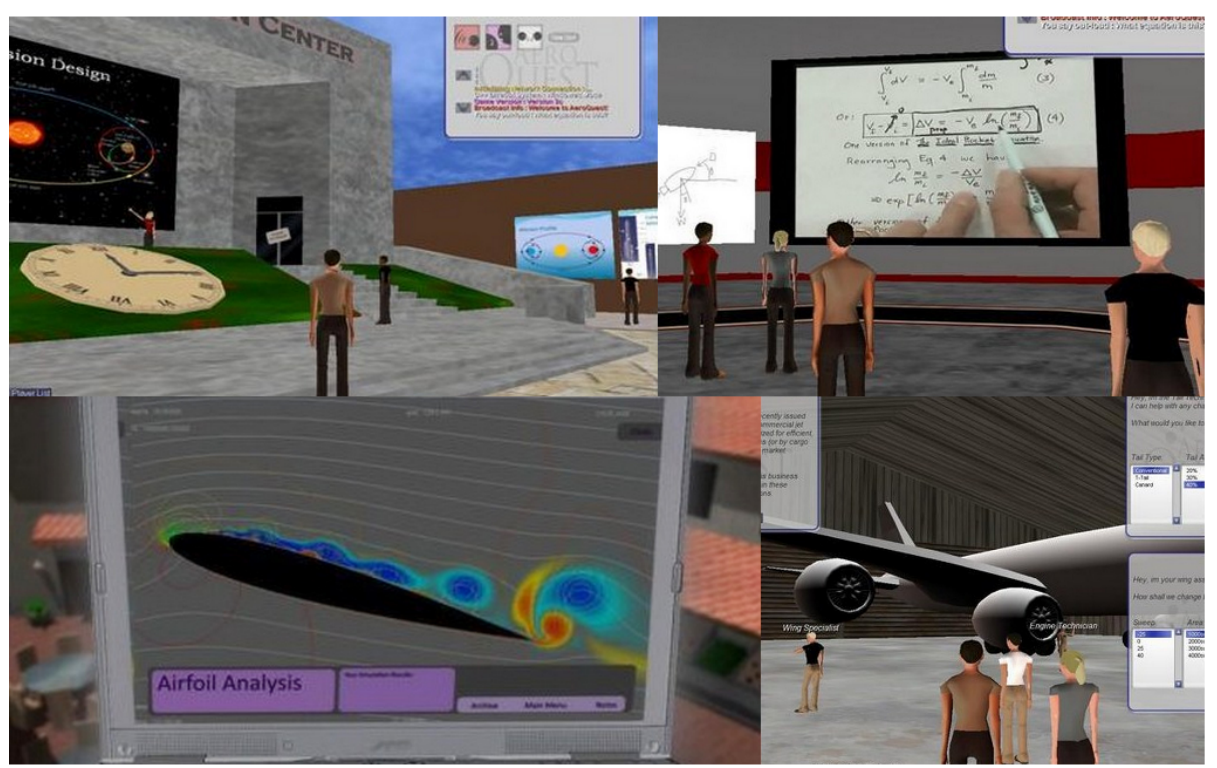

Fig. 1. Educational game for university [10]

students can learn knowledge with their favorite personal tool before or after the class. In this project, the final game will be published on iPhone and iPad devices. The following figure is an example of educational game in iPhone.

In the subsequent sections in the remainder of this paper, we will discuss the game engine in the second section, the game design phases and an education application will be introduced in the third section and a conclusion will be made in the last section.

\section{Game Engine}

The rapid development of computer technology in the last decade has brought a new form to design computer games, which is, game engine [12]. Game engine is a very important component in game design. A game engine directly controls all items in a game, such as the scene, the sound, animation, and so on. The importance of game engine is similar to the importance of an engine for a vehicle. It controls the working of all critical elements in the game according to the game logic or game story. Using a suitable game engine can reduce the design period and can even decrease the design cost. The game designer can simply add related modules to the main framework that is provided by the game engine. It simplifies the work of developing a game system. In this way, the game designer can create a variety of games by using the same game engine, with different characters, scenes, and so on. In the past, computer games were usually developed line-by-line using advanced programming language or a scripting language. 
3D game engine technology has been developed and widely used, not only in 3D game, but also in virtual architecture, education and other areas. The general definition of 3D game engine is as follows: [13]

1. Its output includes graphics, music and effect sounds and its input is the input device.

2. It provides the algorithm to make the character move.

3. It controls various topographies and plays the role of artificial intelligence.

4. It supports the network and monitors numerous functions in the network.

As in the discussion above, the game engine has four main parts, which are, sound, graphics, animation, and artificial intelligence (AI). Each part is an important aspect to a game. A typical diagram for a game engine is shown in Figure 2. [14]

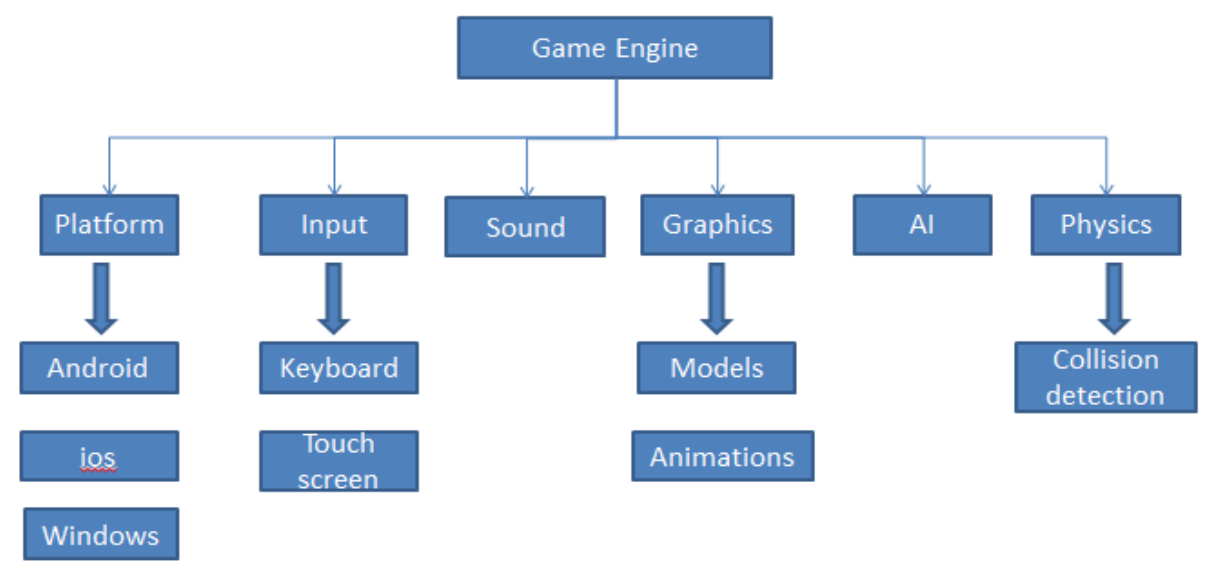

Fig. 2. Feature diagram for a typical game engine

Shiva3D is a popular 3D game engine in recent years, which is very suitable to a 3D game design. Shiva3D game engine provides powerful functionality. In Shiva3D, the graphics rendering, audio, video, editor and other subsystems are included. Figures 3 shows the Shiva3D design platform.

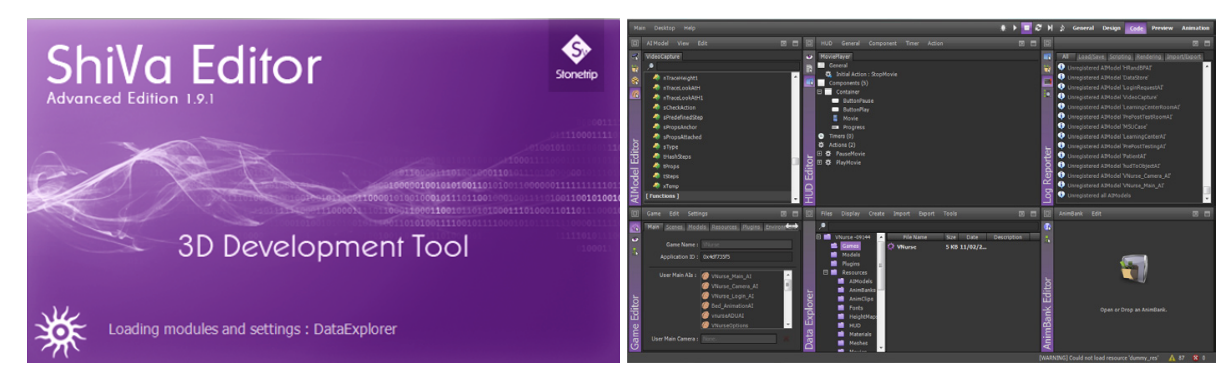

Fig. 3. Shiva3D game engine and Design interface in Shiva3D 
1. Editor: Shiva3D editor has 19 modules. Each module is a tool to create an object, to analyze the application performance, and so on. These modules include AI model editor, AnimBank editor, Game editor and so forth.

2. Script: There are a number of scripts in each game. A script is a class that controls the behavior of a game. [15] A script language called LUA is used in Shiva3D. This script language can support a game on different platforms, such as Windows, Mac, Wii, iPad and iPhone. The game can be played on the web after installing a plug-in in Shiva3D. A script example is shown below.

3. HUD: Heads-up display (HUD) is a visual display technology and a method of visually representing information in a video game. In this project, we will use HUD to display all of the information, concepts, and controlling notes.

\section{Game Design}

\subsection{The basic concepts of game design}

In the design process, designers need to design the game's story, user control, user interface, game level, art, audio and technical features, as well as product features. [16]. The game's technical specifications such as the types of tools that need to be used, should be determined before designing a game. For example, hardware and software need to be determined for design platform. Simultaneously, a suitable programming language for the development of an educational game also needs to be addressed. In the next section, a game engine is discussed for this purpose.

Educational game design includes four important parts that are shown as follows. [16]

1. Educational game interaction: it can be defined as communications between player and game. In this part, HUD, NCP, POV and other contents are included.

2. Educational game knowledge: it can be defined as educational contents that will be delivered to the player via the game. The game designers should know which information should be sent to the players. In other words, this part depends on the content of studying.

3. Educational game engine that is the mechanism of educational content transfer.

4. Educational game level.

\subsection{Phases of game design}

Figure 4 shows the detail of a game design process. First, game designers should know the background of a specific game that they will work on. They also need to know the player who will play this game in the future. For example, the design logic should match to the specific players. Secondly, but just as important, designers must understand the purpose of this educational game before they start working. Because all contents like logic, level, element and other information must support this point. Third, each game needs to be beta tested before it is published in the market. Design- 
ers can discover bugs from the response of players, and optimize or modify the game to make improvements. That many times is the reason why the same game has more than one version - continually improving.

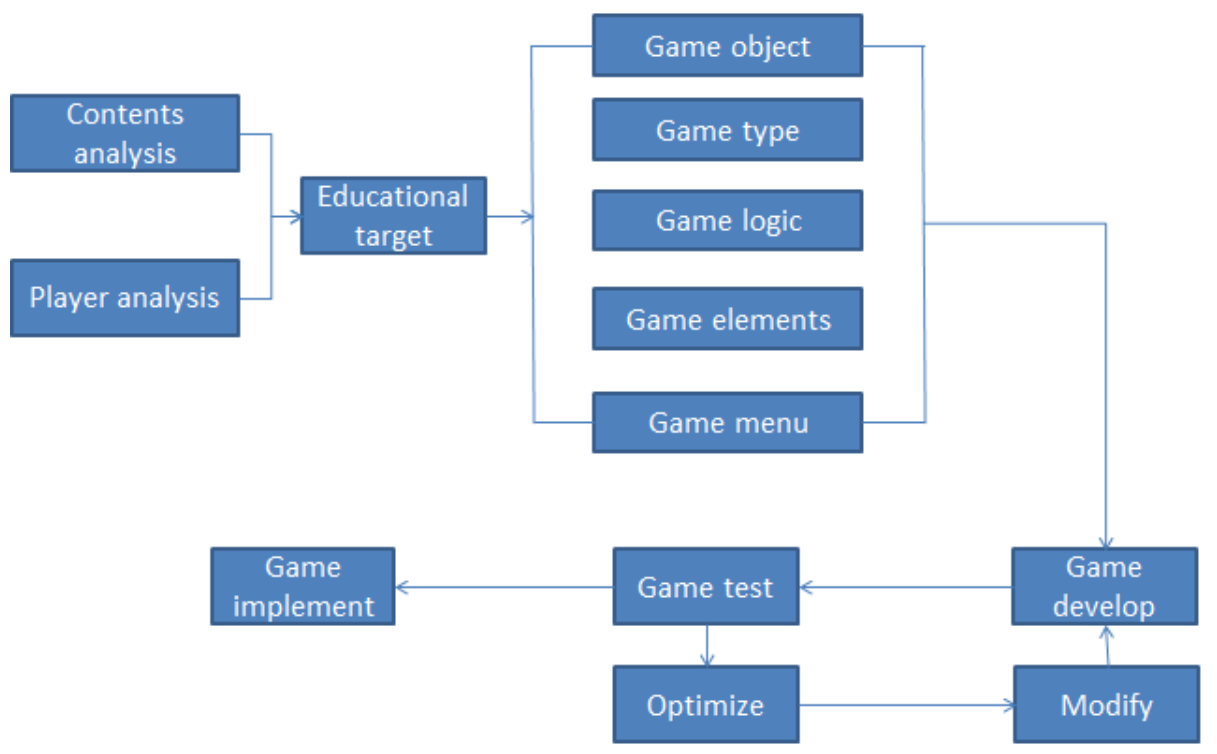

Fig. 4. Game design phases

\section{Design example in education application}

Chemistry is a subject of natural science based on experiments that do research in a large number of chemical phenomena. There are an expansive amount of (NOTE: Avoid the use of "a lot") chemical elements, chemical equations and structures that students need to know and understand. In this case, an educational tool, like an educational game, will be very useful to enhance students understanding and application of knowledge.

Figure 5 is an example for an introduction to Chemistry. Learners can easily glean the chemist's information by clicking the chemist's portrait that is a button. All information can be shown after a click-based button triggers. A portrait of a chemist will setup on a HUD. It is expected that the related information is displayed if the player clicks the portrait. Similarly, the functionality is added to the periodic table. A case example is shown in Figure 6. 


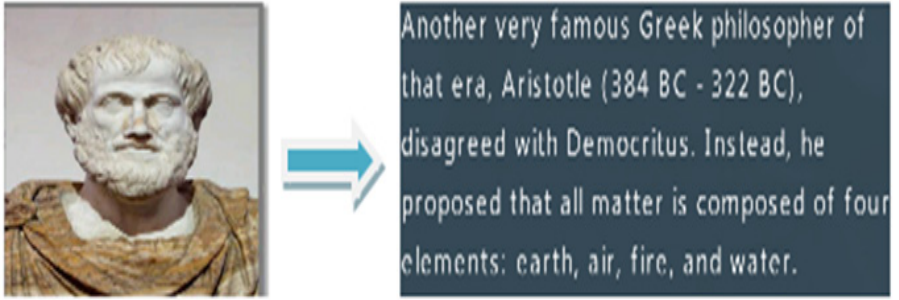

Fig. 5. Chemist button in application

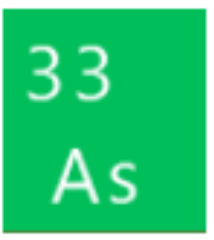

Fig. 6. Button-based chemical element

\section{Conclusion}

From the discussion above, we know that the video game is much more than a game. It can help people to efficiently learn knowledge, form good learning habits, and have fun learning. People who are from diverse areas of study can enjoy a game that is related or unrelated to their field of expertise. Students can easily master theory that they have studied in the class. Video games allow theory and application to connect and broaden horizons. Users such as pilots, engineers and the military can learn key skills that will dramatically increase their safety and reduce their learning curve.

Before designing an education application, the designer should know and understand the information as much as possible. They need to select a suitable game engine, to make game logic, and to design different game levels. So far, educational games are an indispensable teaching-learning tool in the majority of fields. Wellthought out and planned educational game design will make the teaching and learning process consistently more effective.

\section{References}

[1] Annetta, L.A. and Cheng, Meng-Tzu. "Why educational video games?” In. Annetta, L.A. Serious educational games: from theory to practice, Sense Publishers, Rotterdam, 2008.

[2] [2] M. Sloman, "The E-Learning Revolution". London: CIPD, 2001.

[3] T Connolly, M Stanfield, "Using Game-Based elearning Technologies in Overcoming Difficulties in Teaching Information Systems", 《Journal of Information Technology Education》, 2010, 5:459-476.

[4] Y Huang, Y Dong, DH Liu, "Research on educational game design of the blank trial procedure", International Conference on E-education, 2011:249-252. 
[5] M Griffiths , "The educational benefits of video games", 《Education \& Health》, 2002.

[6] V Janarthanan, "Serious Video Games: Games for Education and Health", Ninth International Conference on Information Technology: New Generations, 2012:875-878. https://doi.org/10.1109/itng.2012.79

[7] A.I.Wang,T.Ofsdahl,and O.K.Morch-Storstein. "Anevaluation of a mobile game concept for lectures." In Proceedings of the 21st Conference on Software Engineering Education and Training (CSEET '08), pages 197-204, Charleston, SC, USA, April 2008.

[8] A.1. Wang, O.K. Morch-Storstein, and T. Ofsdahl." Lecture quiz-a mobile game concept for lectures". In Proceedings of the 11th LASTED International Conference on Software Engineering and Application (SEA '07), pages 305-310, Cambridge, Mass, USA, November 2007.

[9] L. Natvig, S. Line, and A. Djupdal. "Age of computers: an innovative combination of history and computer game elements for teaching computer fundamentals". Proceedings of the 34th Annual Frontiers in Education (FIE '04), volume 3, pages 1-6, Savannah, Ga, USA, October 2004. https://doi.org/10.1145/1007996.1008026

[10] https://engineering.purdue.edu/aerohub/images/Collages1.jpg

[11] AI Wang, B Wu, SK Bakken ,"Experiences from Implementing a Face-to-Face Educational Game for iPhone/iPod Touch", Games Innovations Conference, 2010:1-8.

[12] WenFang Chen, Wei Chen, "Game engine applied in education". Computer and Digital Engineering 2008 (09)

[13] Mark Chapman, David Turner, Arturo Concepcion, Aldo Lewis, “Vector Force: A Video game Project", 8th International Conference on Information Technology: New Generations", 2011.

[14] AG Peker, T Can, “A Design Goal and Design Pattern Based Approach for Development of Game Engines for Mobile Platforms", International Conference on Computer Games, 2011:114-120. https://doi.org/10.1109/cgames.2011.6000325

[15] Jingming Xie, "Research on Key Technologies Base Unity3D Game Engine", Computer Science \& Education (ICCSE), 2012 7th International Conference, P. 695-699, July 2012. https://doi.org/10.1109/iccse.2012.6295169

[16] NAM Zin , WS Yue ,"History Educational Games Design", International Conference on Electrical Engineering \& Information, 2009, 01:269-275.

\section{Author}

Sun Hui is currently the faculty of Aviation Automation College at Civil Aviation University of China, Tianjin 300300, China. He got M.S. degree from Norfolk State University, USA. His research interests are Modeling and Game design, Cognitive radio networks, network security, modeling control system (shhappy1@hotmail.com).

Article submitted 22 January 2017. Published as resubmitted by the author 07 March 2017. 